\title{
Use of the polymerase chain reaction in the diagnosis of acquired ocular toxoplasmosis in an immunocompetent adult
}

The Eye Unit,

Southampton SO16 6YD

R M Manners

C R Canning

Department of Molecular Microbiology

Southampton General

Hospital, Southampton

SO9 4XY

s O'Connell

PHLS, Toxoplasma

Reference Laboratory,

Singleton Hospital,

Swansea SA2 8QA

E C Guy

D H M Joynson

Royal Victoria Hospital, Westbourne,

Bournemouth BH4 9DG D E Etchells

Correspondence to:

Miss R M Manners, The Eye Unit, Southampton General Hospital, Southampton SO16 6YD.

Accepted for publication 7 March 1994

\author{
Ruth M Manners, Susan O'Connell, Edward C Guy, David H M Joynson, \\ Christopher R Canning, David E Etchells
}

Gene amplification by the polymerase chain reaction (PCR) is useful in ophthalmic diagnosis since it enables exceedingly small amounts of nucleic acid to be detected in ocular samples. Studies have indicated a potential for the use of PCR on ocular specimens to assist the clinical diagnosis of ocular toxoplasmosis. ${ }^{1}$ We describe a case in which the technique was used in the diagnosis of acquired ocular toxoplasmosis in an immunocompetent adult.

\section{Case report}

A 60-year-old woman complained of blurred vision, photophobia, and floaters in the right eye. She had recently returned from a holiday in Turkey. There was no significant medical history. Two years previously, an incidental examination of the right fundus had shown no abnormality. On examination, the right visual acuity was $6 / 9$. The eye had an anterior uveitis, vitritis, and an area of retinitis inferotemporally. Topical steroids and mydriatics were prescribed and the uveitis settled during the following weeks.

Twelve weeks later the vitritis had increased and the area of retinitis had spread posteriorly. Visual acuity remained unchanged. A diagnosis of acute retinal necrosis was made and treatment commenced with intravenous acyclovir $750 \mathrm{mg}$ three times daily and oral prednisolone $20 \mathrm{mg}$ twice daily. Full blood count, erythrocyte sedimentation rate, urea, and electrolytes were all normal. Complement fixation tests for herpes simplex and herpes zoster antibodies were negative. Antibodies to Toxoplasma gondii were detected at a titre of $1: 256(125 \mathrm{IU} / \mathrm{ml})$ in a dye test and a toxoplasma IgM enzyme linked immunosorbent assay test was positive.

The toxoplasma antibody tests were repeated 10 weeks later with unchanged results. The vitritis was more active and the visual acuity had dropped to counting fingers. Systemic treatment for toxoplasmosis was initiated with pyrimethamine $75 \mathrm{mg}$ loading dose, then $25 \mathrm{mg} /$ day, sulphadiazine $1 \mathrm{~g}$ four times daily, and folinic acid supplementation. Oral prednisolone $10 \mathrm{mg} /$ day was also given. One week later the patient developed a rash with severe itching and the antitoxoplasmal treatment was stopped. The patient was unwilling to have further antitoxoplasmal treatment.

Fifteen weeks later $(81 / 2$ months after initial consultation) she noticed a sudden drop in the vision of the right eye to an acuity of hand movements. Fundus examination was limited because of vitritis, but an ultrasound scan

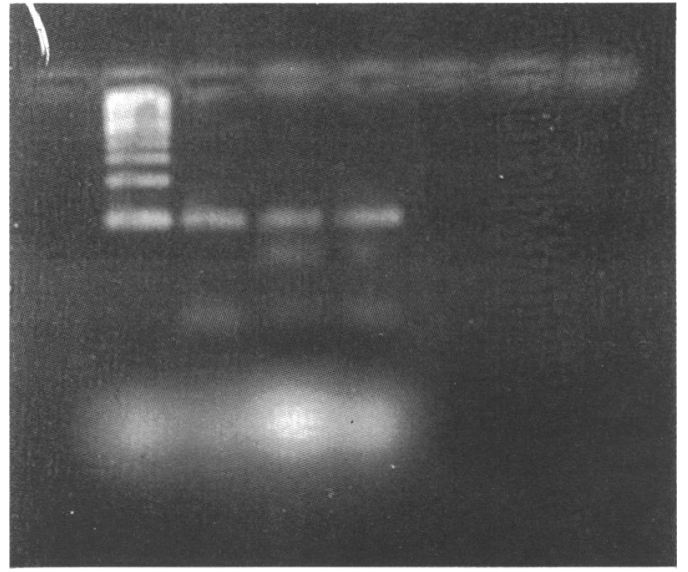

Figure 1 Gel photograph of PCR products. From left to right: track 1, 100 base pair ladder (Gibco); track 2, positive control (T gondii, $R H$ strain); track 3, vitreous of patient (PCR product is 97 base pair in size); track 4, vitreous of patient.

revealed a total retinal detachment. The patient was transferred to the regional vitreoretinal unit and underwent a vitreolensectomy and retinal detachment repair. The retina was found to have multiple holes in the inferotemporal area of chorioretinal scarring and adjacent actively inflamed retina. A vitreous sample was obtained from which DNA was extracted and examined for the presence of $T$ gondii DNA. Nested PCR analysis was performed using four previously described oligonucleotide primers complementary to the $\mathrm{B} 1$ gene. ${ }^{2}$ The PCR products are shown in Figure 1. The $T$ gondii dye, $\operatorname{IgM}$, and IgG avidity tests were performed using standard methods at the PHLS toxoplasma reference laboratory, Swansea. The results are shown in Table 1. The Goldmann-Witmer coefficient was 3.19:1. ${ }^{3}$

Following surgery the eye settled well and all treatment was tailed off. Three months later a visual acuity of $6 / 18$ was attained which has remained stable for 12 months.

\section{Comment}

This patient presented initially with features consistent with acute retinal necrosis but serological investigation 7 weeks after onset showed the presence of $\operatorname{IgM}$ antibodies to $T$ gondii. The sequential profile of the antibody levels in serum, including IgG avidity over 8 months (see Table 1), followed the pattern usually seen in an acquired infection ${ }^{4}$ rather than that of a reactivated congenital infection. An IgG avidity of $32 \%$ is consistent with infection acquired several 
Table 1 Dye test titres, IgM levels, IgG avidity, and total immunoglobulin levels in serum $(S)$ and vitreous $(V)$ samples

\begin{tabular}{llllll}
\hline $\begin{array}{l}\text { Time (weeks) after } \\
\text { onset of symptoms }\end{array}$ & $\begin{array}{l}\text { Dye test } \\
\text { titre }\end{array}$ & $\begin{array}{l}\text { Dye test } \\
(I U / m l)\end{array}$ & $\begin{array}{l}\text { IgM } \\
(I U)\end{array}$ & $\begin{array}{l}\text { IgG } \\
\text { avidity }\end{array}$ & $\begin{array}{l}\text { Total Ig } \\
\text { (g) }\end{array}$ \\
\hline $12(\mathrm{~S})$ & $1 / 256$ & 125 & 75 & $32 \%$ & NT \\
$22($ S) & $1 / 256$ & 125 & 55 & $36 \%$ & NT \\
$37($ S) & $1 / 256$ & 125 & 36 & NT & $12 \cdot 100$ \\
37 (V) & $1 / 16$ & 8 & NT & NT & $0 \cdot 237$ \\
\hline
\end{tabular}

NT= not tested

months previously. An avidity of $40 \%$ is usually seen in infections acquired more than 6 months previously. The Goldmann-Witmer coefficient, ${ }^{3}$ the quotient of relative amounts of toxoplasmal antibodies in vitreous and serum, was 3.19:1. Baarsma $e t a l^{5}$ consider a coefficient of more than 3 to be a positive result, consistent with localised active antibody production in the vitreous, suggesting active disease.

Our patient had no clinical or laboratory findings to suggest any underlying immunological abnormality. It has been suggested that symptomatic acquired toxoplasmosis affecting the eye is rare in the immunocompetent host, although cases have been reported. ${ }^{6}$ Virtually all reported cases had associated systemic features such as lymphadenopathy. Our provisional diagnosis of acquired toxoplasmosis affecting the eye was extremely unusual in an immunocompetent 60 -year-old person with no other symptoms. The presence of toxoplasmal DNA in the vitreous sample, demonstrated by PCR was strong additional supporting evidence.

Part of this work was funded by a research grant from the Toxoplasmosis Trust.

1 Aouizerate F, Cazenave J, Poirier L, Verin P, Cheyrou A, Begneret $\mathrm{J}$, et al. Detection of Toxoplasma gondii in aqueous humour by polymerase chain reaction. Br F Ophthalmol 1993; 77: 107-9.

2 Burg L, Grover CM, Pontethy P, Boothroyd J. Direct and sensitive detection of pathogenic protozoan Toxoplasma sensitive detection of pathogenic protozoan Toxoplasma
gondii by polymerase chain reaction. $\mathcal{F}$ Clin Microbiol 1989; gondit by poly $1787-92$.

3 Witmer R. Clinical implications of aqueous humor studies in uveitis. Am F Ophthalmol 1978; 86: 39-45.

4 Joynson DHM, Payne RA, Rawal BIC. Potential role of IgG avidity for diagnosing toxoplasmosis. $\mathcal{F}$ Clin Pathol 1990; 43: 1032-3.

5 Baarsma GS, Luyendijk L, Kijlstra A, de Vries J, Peperkamp $\mathrm{E}$, Mertens DAE, et al. Analysis of local antibody production in vitreous humor of patients with severe uveitis. Am $\mathcal{F}$ Ophthalmol 1991; 112: 147-50.

6 Saari M, Vourre I, Niminem H. Acquired toxoplasma chorioretinitis. Arch Ophthalmol 1976; 94: 1485-90.

\title{
Aspergillus niger as an unusual cause of scleritis and endophthalmitis
}

\author{
Martine J Jager, James Chodosh, Andrew J W Huang, Eduardo C Alfonso, William W \\ Culbertson, Richard K Forster
}

Bascom Palmer Eye Institute, University of Miami, Miami, USA M J Jager

J Chodosh

A J W Huang

E C Alfonso

W W Culbertson

R K Forster

Department of Ophthalmology, Leiden University, Leiden, the Netherlands

M J Jager

Correspondence to:

Martine J Jager, MD

Department of

Ophthalmology, AZL, Leiden

University, PO Box 9600, 2300

RC Leiden, The Netherlands.

Accepted for publication

8 February 1994
Ocular infections with Aspergillus species are associated with keratitis and sporadically with endophthalmitis. In addition, Aspergillus is an uncommon cause of infectious scleritis. We describe here a patient who developed an $A$ niger infection of the sclera possibly caused by drug abuse or automutilation. The infection progressed to endophthalmitis. No similar infection with $A$ niger has been reported to our knowledge.

\section{Case report}

A 35-year-old white woman presented with a 3 month history of a painful red right eye associated with severe right sided headache. Earlier diagnostic evaluation included a computed tomography scan of the head and paranasal sinuses, lumbar puncture, chest radiogram, serological tests for syphilis, Lyme disease, collagen vascular disease, and rheumatoid arthritis, as well as a tuberculin skin test. All results were unremarkable. Treatment with prednisone ( $80 \mathrm{mg} /$ day) for presumed idiopathic scleritis was begun with initial improvement, but had to be discontinued because of systemic side effects.

The patient was referred to the Bascom Palmer Eye Institute in February 1992 with a recurrence of the pain around the right eye. Examination showed a visual acuity of 20/20 in both eyes. A focal area of anterior scleritis with a bluish tinge was noted in the inferotemporal quadrant of the right eye. Ophthalmic examination was otherwise normal in both eyes. A subconjunctival injection of $0.5 \mathrm{ml}$ triamcinolone $(40 \mathrm{mg} / \mathrm{ml})$ was placed adjacent to the scleritis, which led to improvement. The patient subsequently received periocular steroid injections every 3 weeks, given by her private ophthalmologist.

Ten months later she was referred again, this time because of decreased vision and an unusual anterior chamber infiltrate in the right eye, for which she had been treated with prednisolone acetate $1 \%$ every hour and diclofenac sodium $0 \cdot 1 \%$, four times a day, without improvement. Visual acuity was 20/70 in her right eye, and the anterior chamber showed fluffy material 